\title{
THE GLENOID LABRUM AS A SOURCE OF LOOSE BODIES IN THE SHOULDER
}

By L. C. L. GoNeT, M.B., B.S., F.R.C.S.

First Assistant, Orthopaedic and Traumatic Dept., West Middlesex Hospital

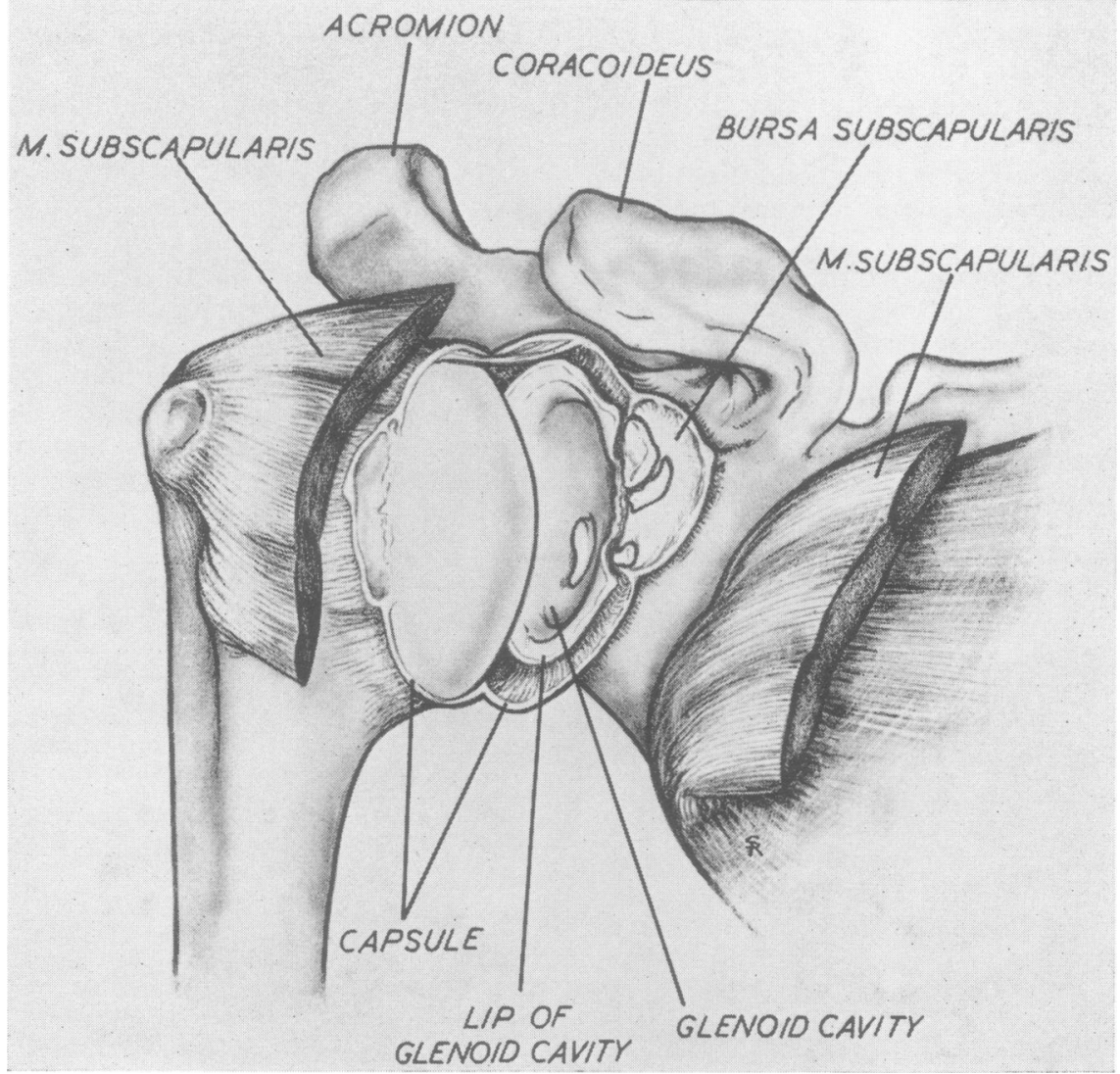

Fig. I.

\section{Case History}

A healthy lad of 18 years sustained a subcoracoid dislocation of the right shoulder in November 1954. He slipped, caught his elbow in a rack and fell backwards, twisting his shoulder at the same time. The dislocation was reduced under general anaesthesia by Kocher's method. Subsequently there was a recurrence of the dislocation four times in the ensuing year.

On November 17, 1955, an open operation was performed for the repair of what was believed $t \tilde{\Theta}$ be a Bankart lesion. The glenoid labrum was in fact, found to be detached and a gap of $2 \mathrm{~cm}$ was occupied by one loose body, two loose bodies were in the subscapular bursa and a fourth was found in the shoulder joint itself (Fig. I). These put together could be made to fit the defect in the glenoid labrum almost exactly. It was onlyc possible to suture a portion of the torn labrums with a drill hole and nylon suture, and a Putti两 


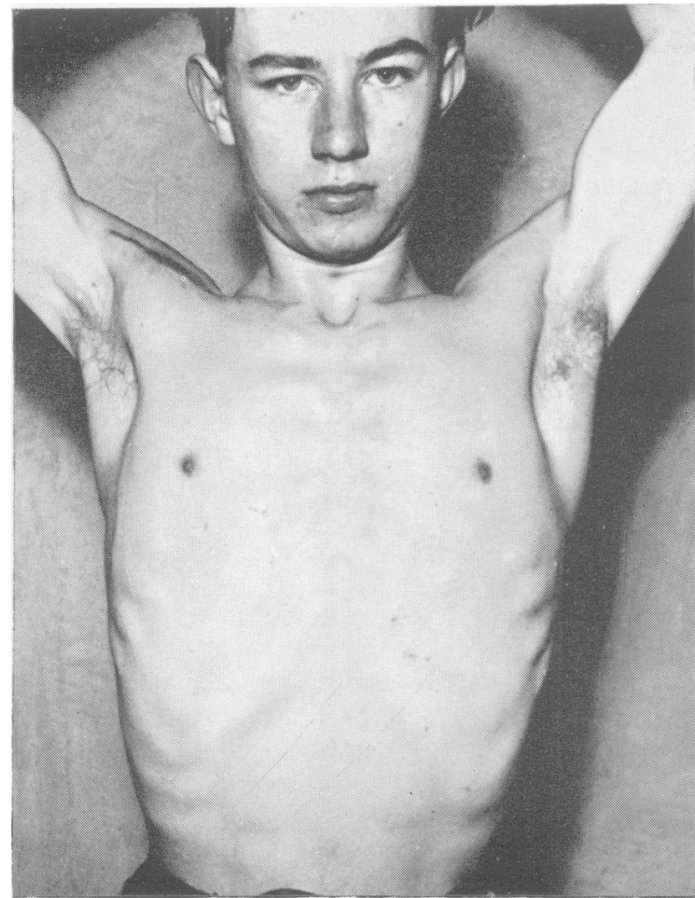

FIG. 2.

Platt repair was performed after removal of the loose bodies.

His subsequent progress has been uneventful and satisfactory and no recurrence of the dislocation has occurred (Fig. 2).

\section{Comment}

The unusual feature of this case is the presence of these fibro-cartilaginous loose bodies (Fig. 3), which were almost certainly from the torn glenoid labrum and which would bear out the correctness of the Bankart lesion. There was no evidence that these had come from the head of the humerus or from the glenoid rim. Section of part of one loose body showed it to be of fibro-cartilaginous material.

Very few writers mention the presence of loose bodies, and those that have have attributed them to bony defects seen in the head of the humerus or the glenoid. Watson-Jones records the presence

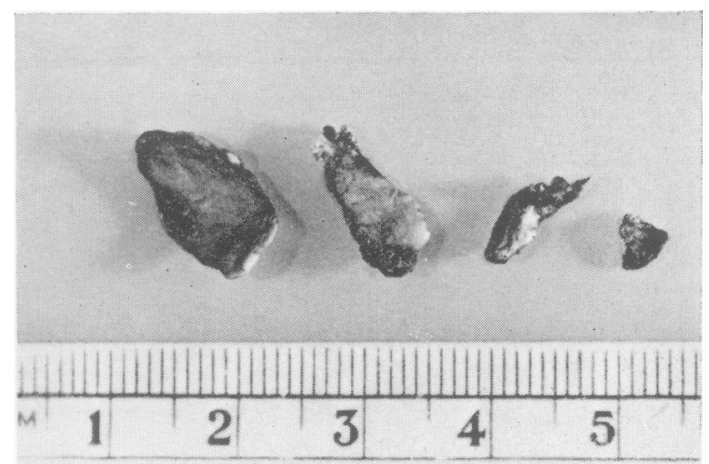

FIG. 3.

of two loose bodies and Boost and Inman describe a loose cartilaginous body $2.1 \times 1.0 \times 0.5 \mathrm{~cm}$. in size, which was present anteriorly. The origin was not proved but was thought to originate from the postero-lateral defect of the humeral head. Du Toit and Roux in a very recent article state that ... ' in several patients small loose bodies were removed from the joint, these bodies having been derived from the antero-inferior surface of the glenoid margin.' P. Leguit of Amsterdam observes that 'loose bodies are seldom encountered. They generally consist of a piece of bone that has been detached from the lower rim of the cavity.'

\section{Conclusion}

In the above cases the lesion was only a year old from the history of events but there was no evidence of the loose bodies on the original X-rays (taken in conventional views and in 60 degrees internal rotation) nor a year later. It would seem that a repair other than one which opens the joint would in many cases overlook this interesting finding.

\section{BIBLIOGRAPHY}

BANKART, A. S. B. (1938), Brit. F. Surg., 26, 23.

GARTLAND and DOWLING (1954), Clinical Orthopaedics, No. 3,86 .

BOOST and INMAN (1942), $\mathcal{f}$. Bone $f t$ Surg., 24, 595.

CRAWFORD ADAMS, J. (1948), Ibid., 30b, 26.

EYRE BROOK, A. (1948), Ibid., 30b, 39.

WATSON-JONES, R. (1948), Ibid., 30b, 6 et 49.

DU TOIT and ROUX (1956), Ibid., 38a, No. I p. 1.

LEGUIT, P. (1953), $\mathcal{F}$. int. Coll. Surg., 20, 741, December.

KING, T. (1947), 'Recurrent Dislocation of Shoulder,' Med. F. of Aust., June 7, 697. 